\title{
دراسة الإحتياجات التعليمية للأخصائيين الإرشاديين الزراعيين في مجال التلوث البيئي ويعض العوامل المؤثرة عليها بمحافظة البحيرة
}

\section{كمال صلاح عيسى صقر}

قسم الإقتصاد الزراعي - كلية الزراعة ( سابا باشا ) - جامعة الإسكندرية

الملخص:

بستهدف هذا البحث بصفة رئيسية دراسة الإحتياجات التعليمية للأخصائيين الإرشاديين في مجال التلوث البيئي فيما يتعلق باستخدام المبيدات والأسمدة الكيماوية بمحافظة البحيرة ، وتم جمع البيانات البحثية عن طريق الإستنيان بالمقابلة الثخصية لجميع الأخصائيين الإرشاديين الزراعيين بمحافظة البحيرة وعددهم ( 44 باسئه ) أخصائي ، وتمثلت الأسـاليب الإحصـائية المستخدمة في : المتوسـ الحسـابي ، والجداول التكراريـة ، والنسـب المئويـة ، ومعامل الإرتباط البسيط ( لبيرسون ) ، ومعامل الإنحدار المتعدد. وقد أوضحت النتائج البحثنية ما يلي: - تبين أن (86,36\%) ذوي مستوى إحتياجات تعليمية متوسطة ومرتفعة فيما يتعلق بصيانة البيئة من التلوث بالمبيدات والأسمدة الكيماوية. - تبين وجود علاقة إرتباطية معنوية عكسية بين درجة الإحتياجات التعليمية للأخصائيين الإششاديين في مجال

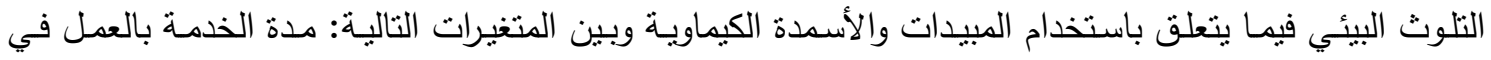
مجال صيانة البيئة من التلوث ، ومدي التعرض لدورات تدريبية في مجال صيانة البيئة من التلوث ، والرضـا

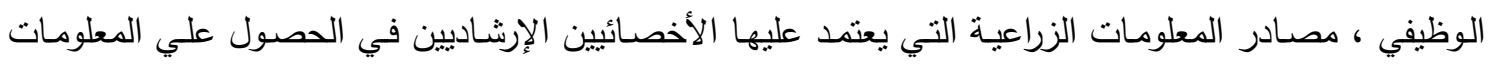

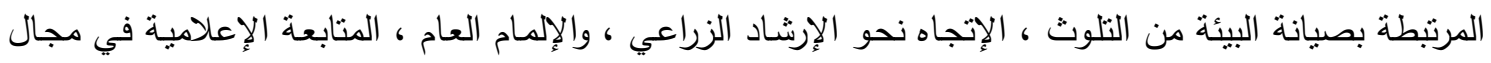
صبانة البيئة من التلوث بالأسمدة والمبيدات. - تبين وجود بعض المشكلات التي تواجه الأخصائيين الإرشاديين في مجال التلوث البيئي فيما يتعلق باستخدام

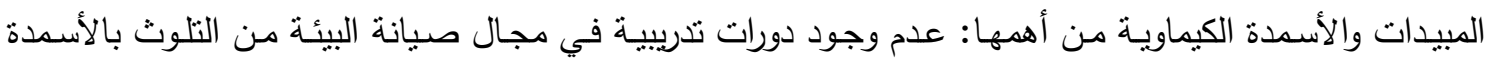

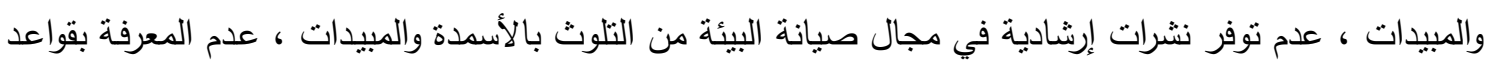

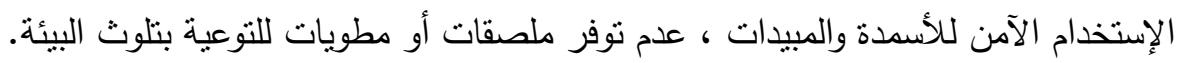

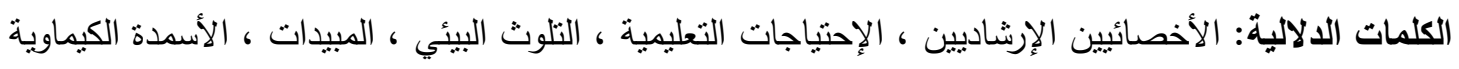

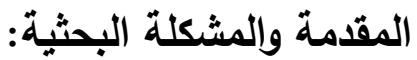

تعد التتمية هي الهدف الأساسي الذي تسعى إلية المجتمعات المنقدمة والنامية ، ولاثك ان الزراعة هي المحرك الرئيسي لعملية التتمية في الدول النامية ، وتأتي التتمية في مصر مدفوعة بالتحولات الإقتصادية والتحديات

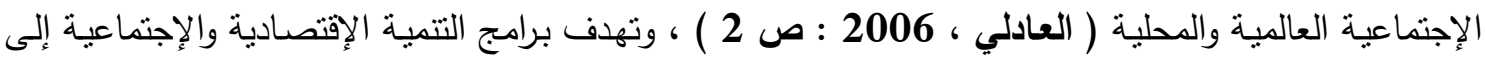
تحقيق الرفاهية للسكان من خلال توفير المدخلات وتطوير التقنيات التي تؤدي لزيادة إنتاجية الموارد وحسن إدارتها

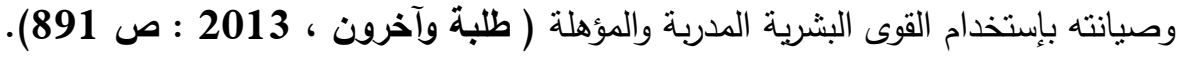


وعندما يتدخل الإنسان في البيئة دون وعي ويحدث فيها تأثثراته السلبية يخل توازنها وتظهر المشكلات

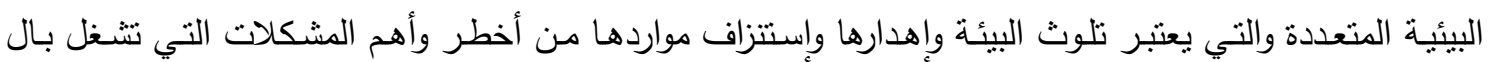

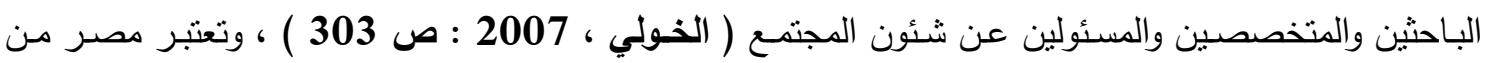
أكثر الدول العربية إستهلاكاً للأسمدو الكيماوية ، حيث تستخدم حوالي ( 2021967 ) طن سنوياً من الأسمدة الآزوتيـة ، وحوالي ( 1744627 ) طن من الأسمدة الفوسفانية ، و ( 80663 ) طن من الأسمدة البوتاسية ، بالإضافة الى ( الإونه وحولي ( 205850 ) طن من الأسمدة المركبة ( نشرة إحصاءات مستلزمات الإنتاج الزراعي ، 2012 :

أما الإستخدام المكثف للمبيدات الزراعية في مصر فقد أدى لكثير من المشكلات البيئية والصحية للإنسان والحيوان والنبات ، كما ادي لتدهور التربة الزراعية مع مرور الوقت ، وقد تبين أن المحافظة على التربة الزراعية من التدهور كأهم مورد طبيعي ونادر وترشبي إستخدامها لتحقيق أكبر إستفادة منها ، يحفظ حق الأجيال القادمة فيها

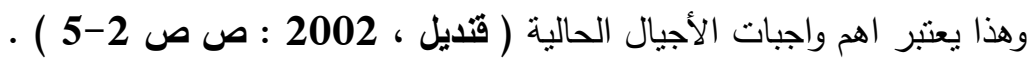

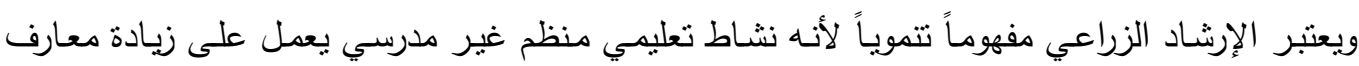

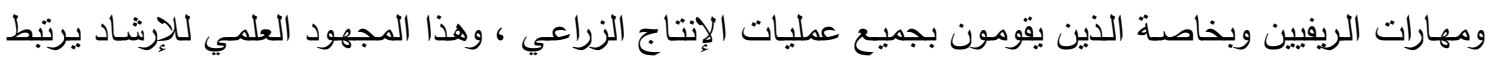

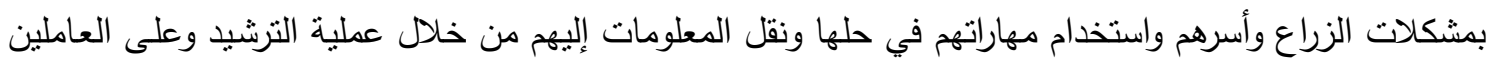

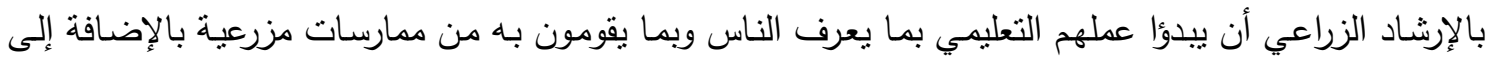

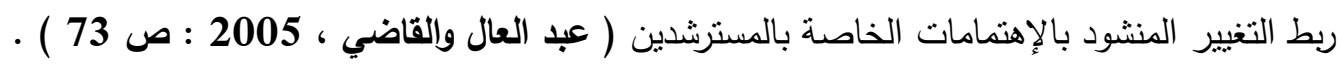

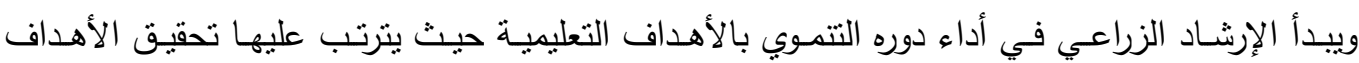
الإرشادية الأخري ، فالأهداف التعليمية مباثرة وتركز على إحداث التغييرات السلوكية المرغوبة للزراع وهي تميز

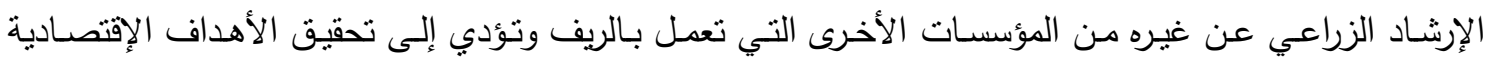

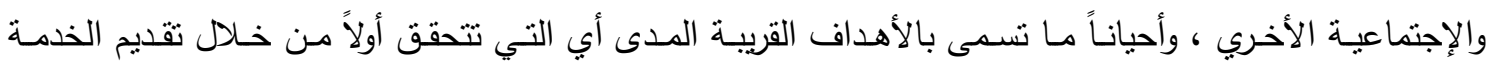

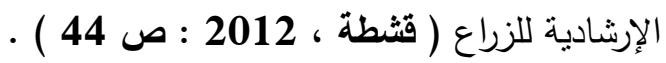
فالتعلم يمثل الجزء الأساسي في نشـاط الإرشـاد الزراعي ، ويترتب عليها تحقيق الأهداف الإقتصـادية

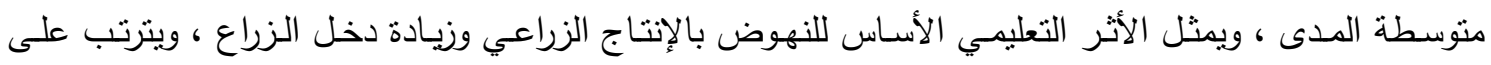

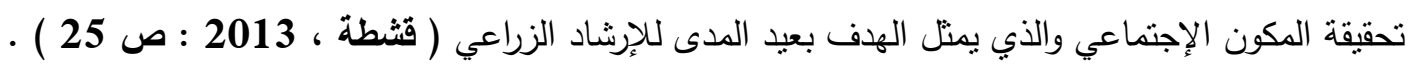

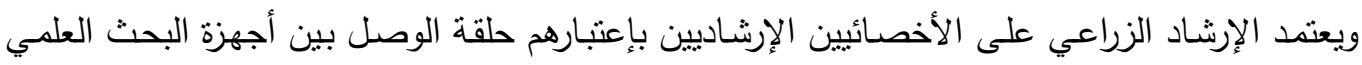

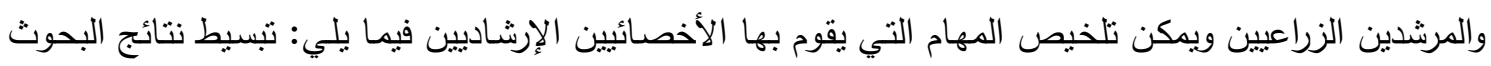

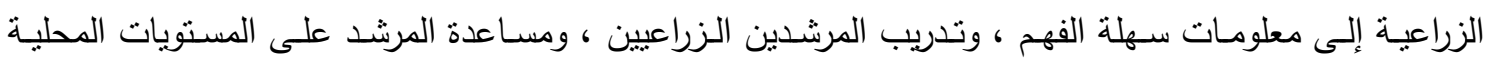

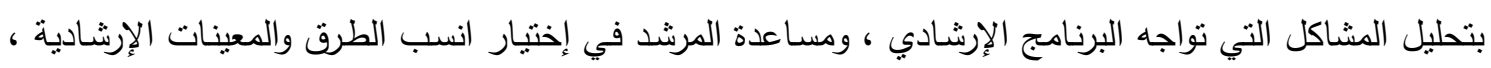

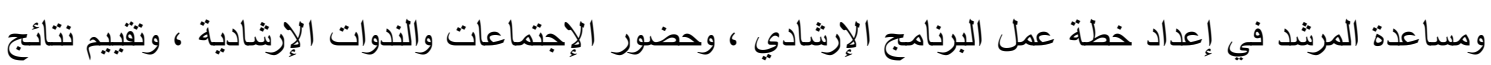

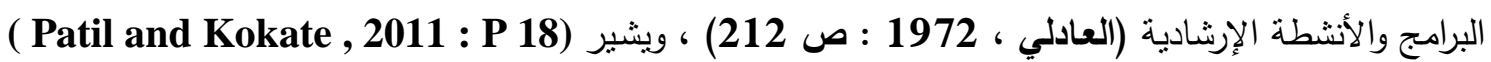

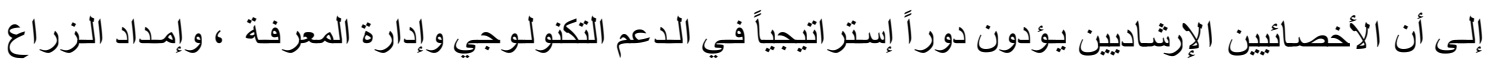

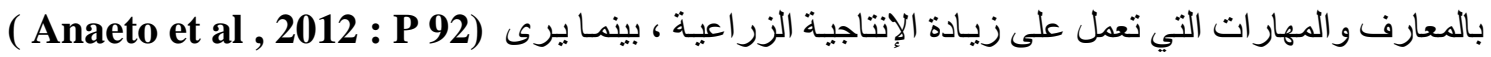

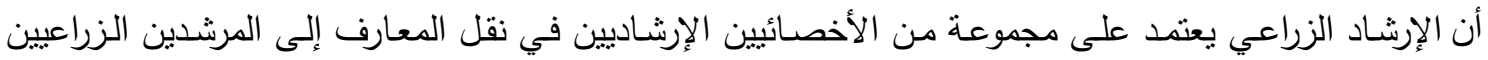
بالإضافة إلي نتائج البحوث الزراعية المختبرة وتدريبهم عليها. 
وإستتاداً لما سبق فإن مبررات هذا البحث تتمثل في تحديد الإحتياجات التعليمية للأخصائيين الإرشاديين

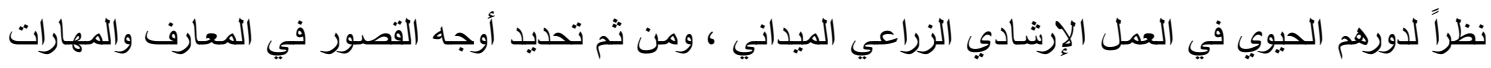

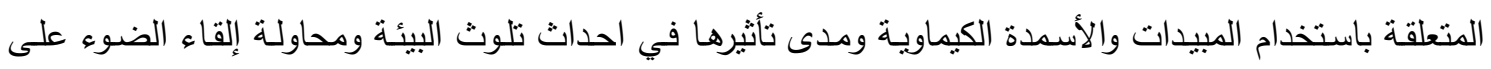
خطورة الإستخدام غير الرشيد للمبيدات والأسمدة الكيماوية وما يترتب علية من مشاكل بيئية خطيرة ، وأيضاً إبراز الإتجاهات الحديثة في مجال المحافظة على البيئة من التلوث فيما يتعلق بإستخدام المبيدات والأسمدة الكيماوية.

\section{الأهداف البحثية:}

يستهدف هذا البحث بصفة رئيسية دراسـة الإحتياجـات التعليمية للأخصـائيين الإرشـاديين في مجال التلوث

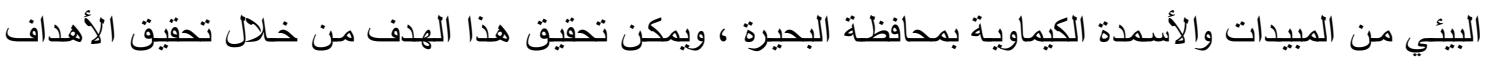
الفرعبة التالية:

1- التعرف علي بعض الخصائص الثخصية والمهنية المميزة للأخصائيين الإششاديين الزراعيين.

2-تحديد الإحتياجات التعليمية للأخصائيين الإرشاديين الزراعيين.

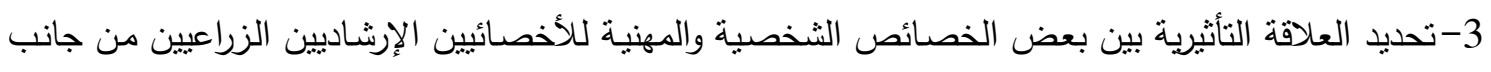
والإحتياج البيئي من جانب آخر . 4- التعرف على المشاكل التي نواجه المبحوثين في مجال البيئة والحلول المقترحة لها من وجهة نظرهم.

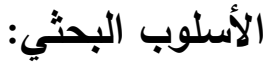

\section{التعريفات الإجرائية للمصطلحات البحثية وطرق قياسها:}

1-الأخصائي الإرشادي: ويقصد بـه في هذا البحث الثخص الذي تم تعيينه وحصل على دورات تدريبية تؤهلة ليقوم بعمل الأخصائي الإرشادي الزراعي بمحافظة البحيرة. 2-الإحتياجات التعليمية: ويقصد بها في هذا البحث نواحي القصور أو النقص في المعارف والمهارات والإتجاهات

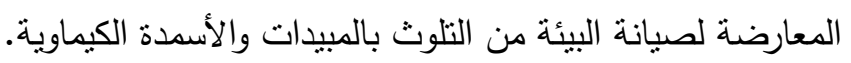

3- السن: ويقصد به في هذا البحث عمر المبحوث حتي وقت إجراء هذا البحث مقدراً بالسنوات. 4- المؤهل الدراسـي والتخصص: ويقصد بـه المؤهل الذي حصل عليـه المبحوث من حيث كونـه مؤهل زراعي منوسط ، أو عالي ، أو فوق عالي ويعطى المبحوث قيمة رقمية واحدة لكل سنة دراسية قضاها المبحوث بالمراحل

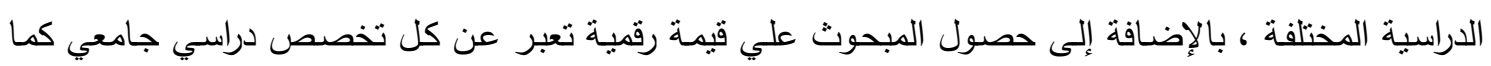

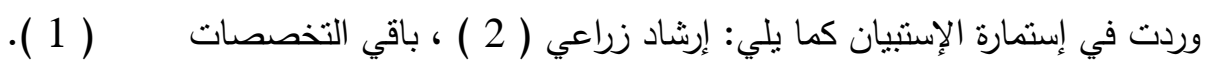
5- مدة الخدمة بالعمل الزراعي: ويقصد بها عدد السنوات التي قضاها المبحوث بان بالعمل الزراعي من تاريخ تعيينه ويعطي المبحوث قيمة رقمية واحدة لكل سنة. 6-مدة الخدمـة بالعمل الإرشـادي الزراعي: ويقصد بها عدد السنوات التي قضـاها المبحوث بالعمل الإرشـادي الزراعي ويعطي المبحوث قيمة رقمية واحدة لكل سنة. 7-مدة الخدمة بالعمل في مجال صيانة البيئة من التلوث: ويقصد بها عدد السنوات التي قضاها المبحوث في مجال صيانة البيئة من التلوث ويعطي المبحوث قيمة رقمية واحدة لكل سنة.

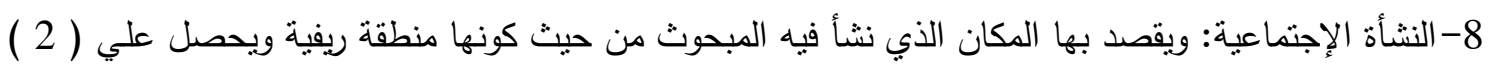
درجة ، أو منطقة حضرية ويحصل علي ( 1 ) درجة. 
9- التعرض لدورات تدريبية في مجال صيانة البيئة من التلوث: ويقصد به مدي تعرض المبحوث لدورات تدريبية

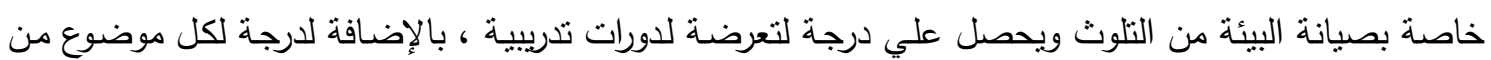

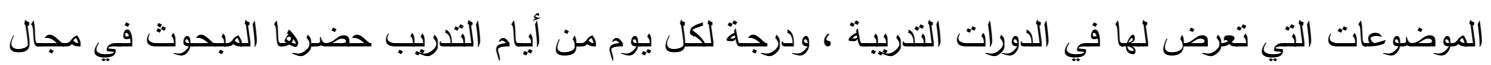

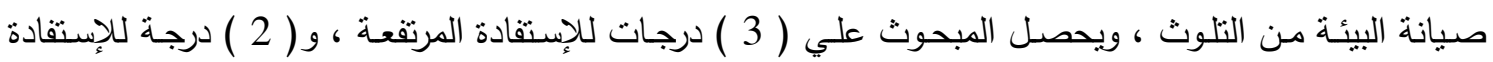
المتوسطة ، و ( 1 ) درجة للإستفادة المنخفضة ، و ( صفر ) درجة لعدم إستفادته من هذة الدورات ، ويحصل

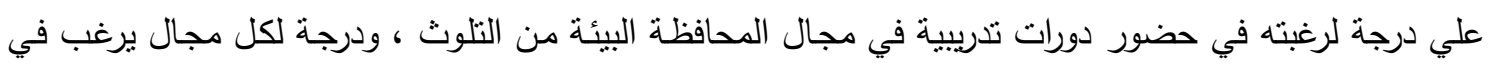

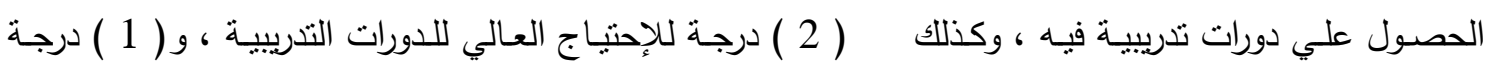
للإحتياج التدريبي المتوسط ، و (صفر ) درجة للإحتياج التدريبي المنخفض. 10- الرضـا الوظيفي: ويقصد بـه مدي قبول المبحوث لوظـائفه ورغبتهم في الإستمرار فيها وإتجاهـاتهم نحوهـا

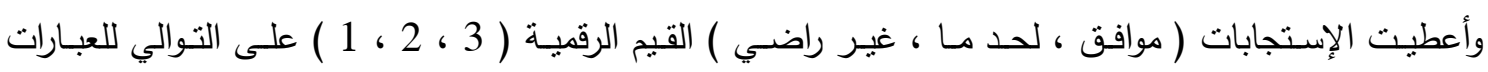
الإيجابية ، والعكس صحيح للعبارات السلبية. 11- مصادر المعلومات الزراعية : ويقصد بها المصادر التي يستقي منها المبحوث المعلومات الفنية المرنبطـة

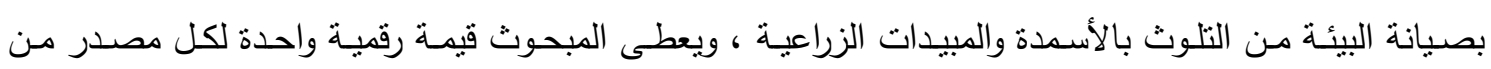
المصادر التي ذكرها. 12- الإتجـاه نحو الإرشـاد الزراعي : ويقصد بـه مدى إيجابيـة أو سلبية أو حياديـة المبحوث نحو العمل داخل

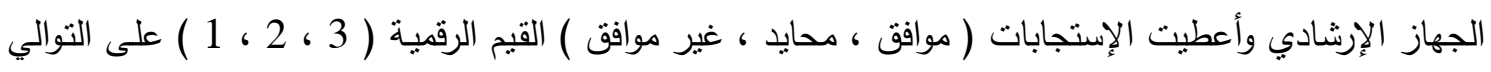
للعبارات الإيجابية ، والعكس صحيح للعبارات السلبية. 13- الإلمام العام: ويقصد به في هذا البحث مدي إجادة معرفة المبحوث بعدد من العبارات تعكس الإلمام العام لـه

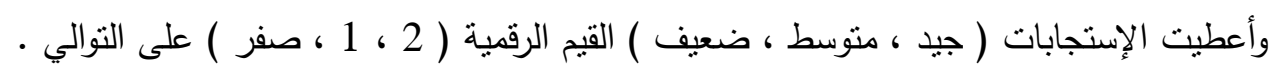

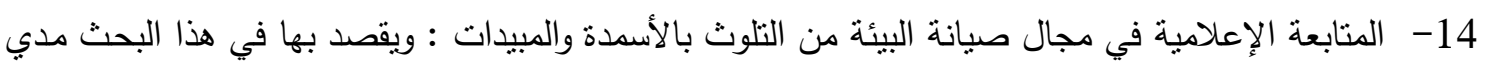

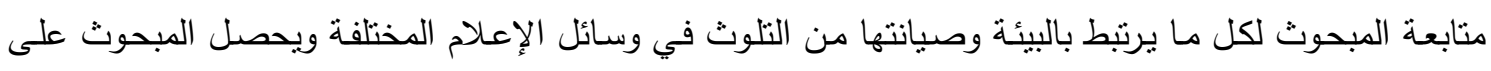
قيمة رقمية كالتالي : درجة واحدة لكل مشكلة بيئية يذكرها ، ودرجة على كل اسم مبيد محرم يذكرة ، ودرجة واحدة لكل إجابة صحيحة يذكرها لباقي العبارات. 15- الإحتياجات التعليمية للمبحوثين في مجال التلوث البيئي بالأسمدة والمبيدات الزراعية : ويقصد بها في هذا

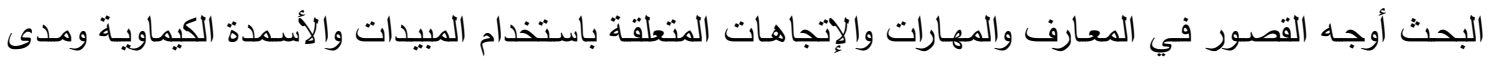
تأثيرها في احداث تلوث البيئة وأعطيت الإستجابات ( لا توجد معرفة ، معرفة محدودة ، معرفة متوسطة ، معرفة

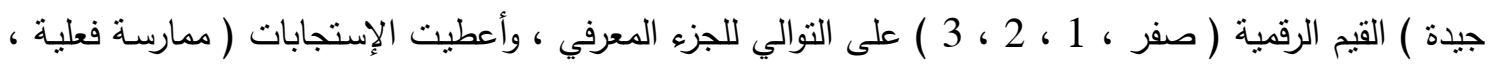
نظريـة فقط ، لا يعرف ) القيم الرقمية ( 2 ، 1 ، صفر ) ) على التوالي للجزه المهاري ، وأعطيت الإستجابات (

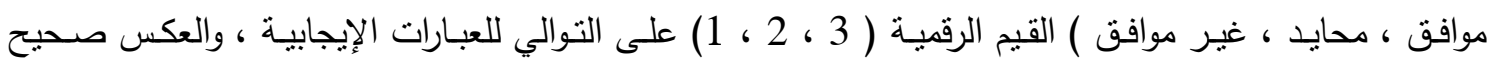

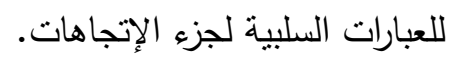




\section{الفروض البحثية :}

لتحقيق أهداف هذا البحث تم صياغة الفروض البحثية التالية:

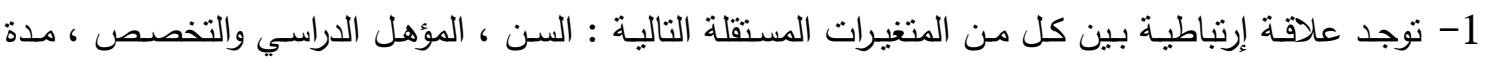

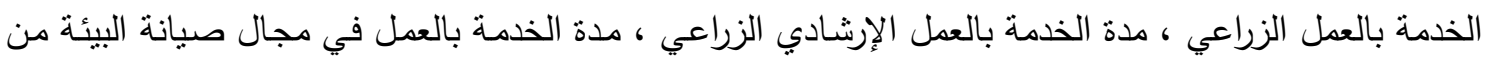

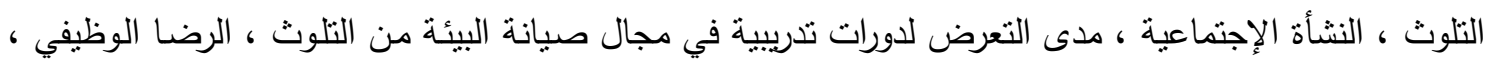

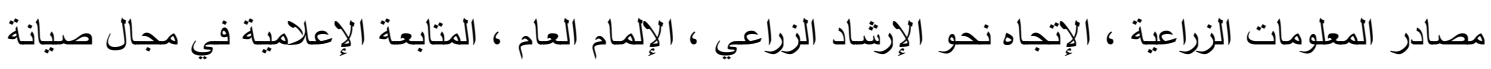

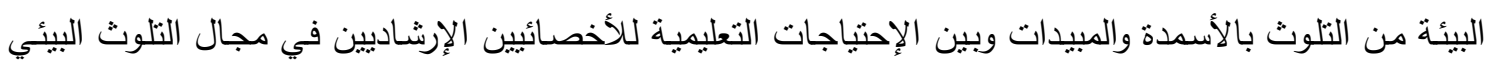

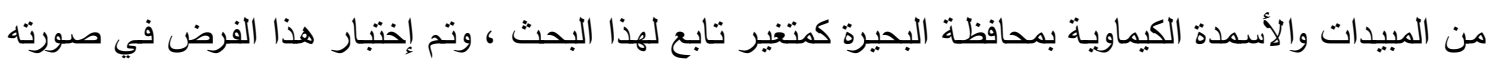
الصفرية.

2- نوجد علاقة تأثنرية بين الإحتياجات التعليمية للأخصائيين الإرشاديين في مجال التلوث البيئي من المبيدات والأسمدة الكيماوية بمحافظة البحيرة كمتغير تابع لهذا البحث وبين المتغيرات المستقلة السابق ذكرها ، وتم إختبار هذا الفرض في صورته الصفرية.

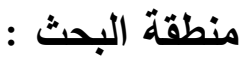

أجري هذا البحث في محافظة البحيرة ، وهي إحدي محافظـات الوجـه البحري والتي تعد من أكبر المحافظات

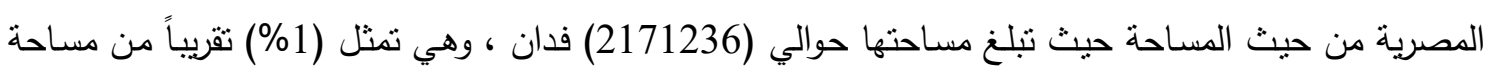

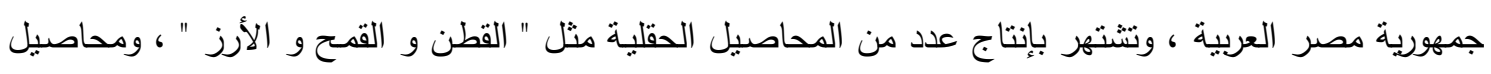

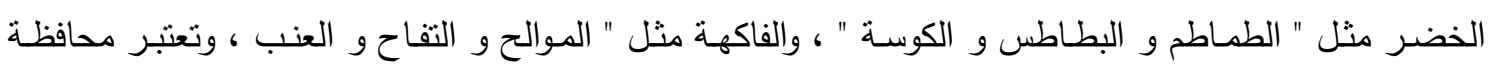

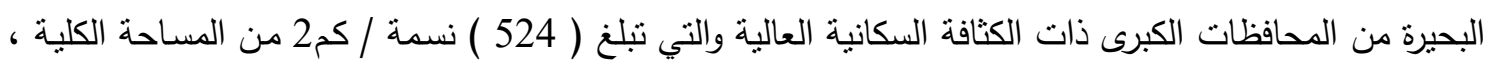

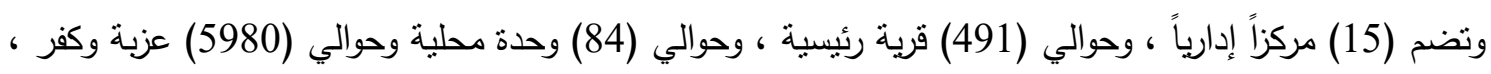

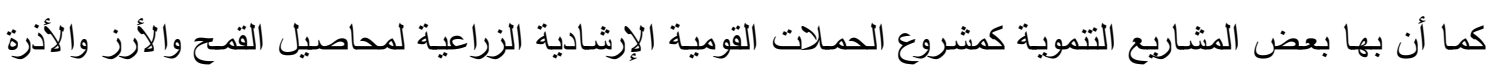
ومثروع التتمية الريفية بالبحيرة.

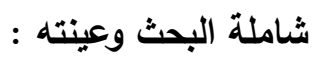

تمثلت شاملة البحث وعينته في جيع الأخصائيين الإرشاديين الزراعيين في محافظة البحيرة والبالغ عددهم ( 44 )

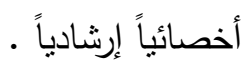

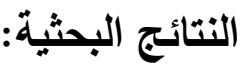

أولاً: بعض الخصائص الثخصية والمهنية للأخصائيين الإرشاديين الزراعيين:

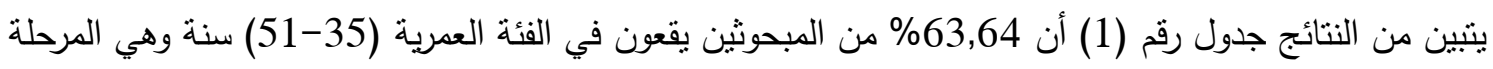

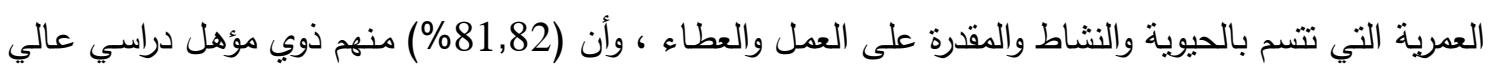

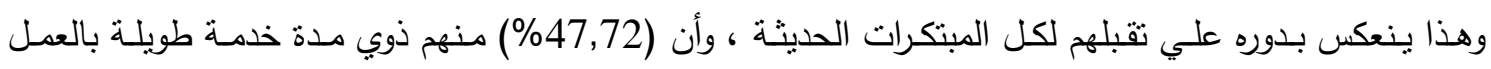

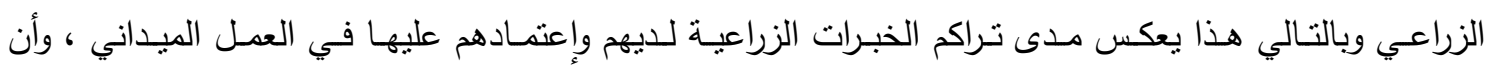

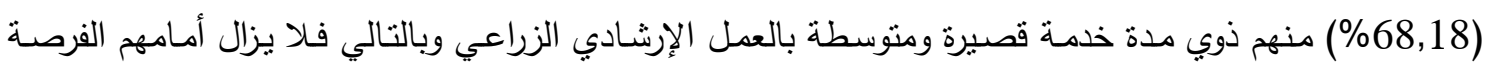

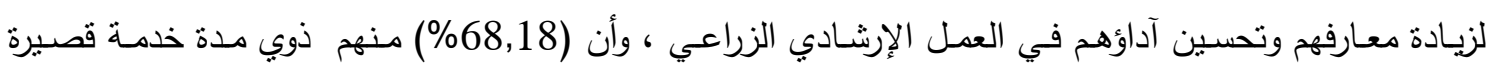

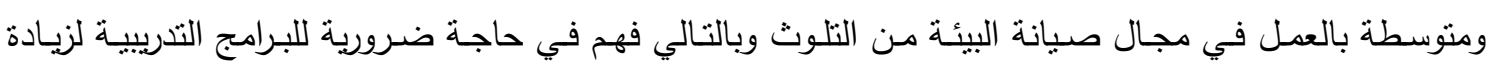




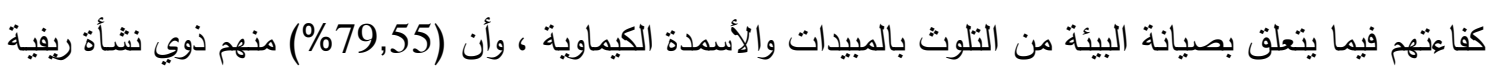

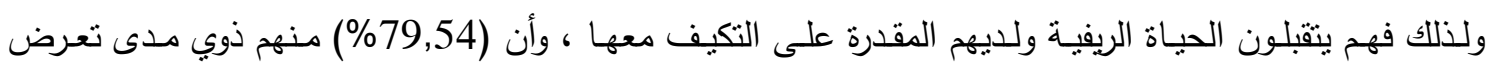

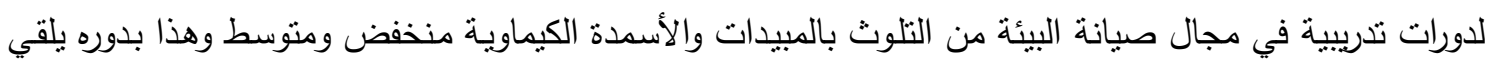
الضوء على ضرورة عقد المزيد من الدورات التدريبية والبرامج الإرشادية الزراعية المتعلقة بصيانة البيئة من التلوث

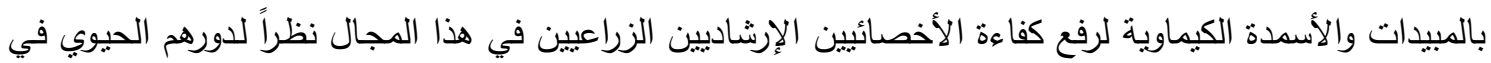

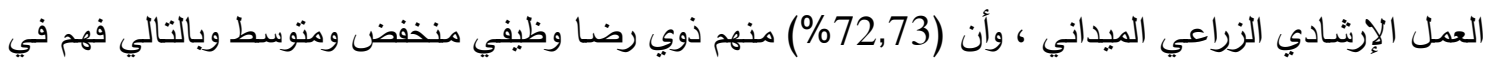

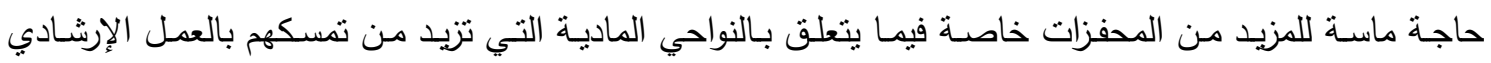

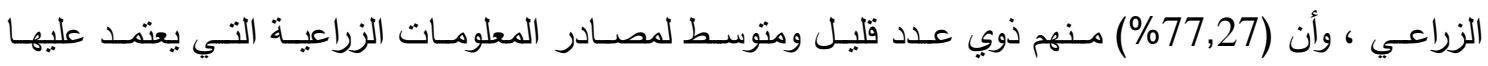
الأخصـائيين الإرشـاديين في الحصـول علي المعلومـات المرنبطة بصيانة البيئة مـن التلوث بالمبيدات والأسمدة

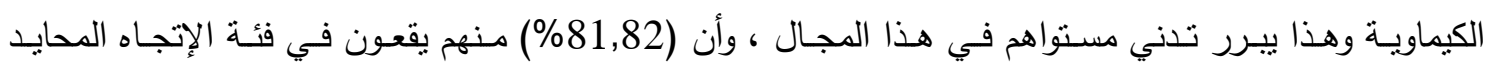

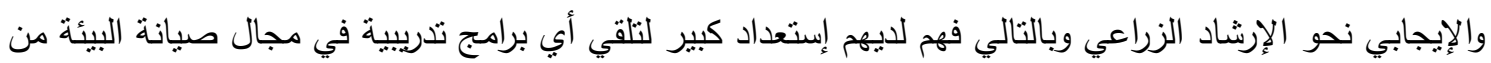

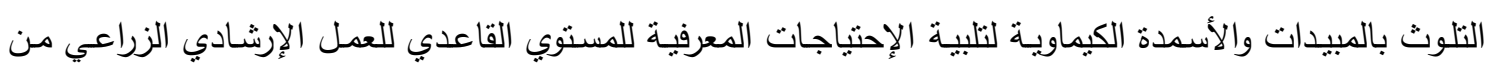
مرشدين وزراع ، وأن (70,45\%) منهم ذوي إلمام عام منخفض ومتوسط وهذا يظهر تدني مستوي المبحوثين فيما

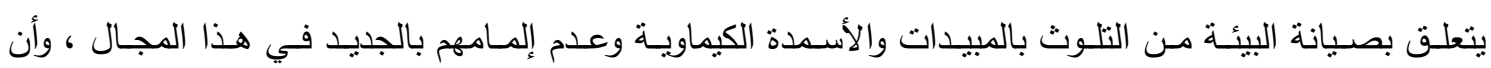

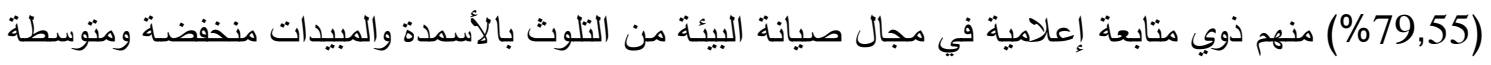
وبالتالي فهم يعانون من نقص في المعارف المتصلة بهذا المجال بما يؤثز بالسلب على من بيتلى منهم التوصيات الإرشادية الزراعية من مرشدين وزراع وبالتالي يحدث تدهور للبيئة نتيجة لتلوثها بالمبيدات والأسمدة الكيماوية.

جدول رقم (1). توزيع الأخصائيين الإرشاديين الزراعيين المبحوثين وفقاً لخصائصهم الثخصية والمهنية

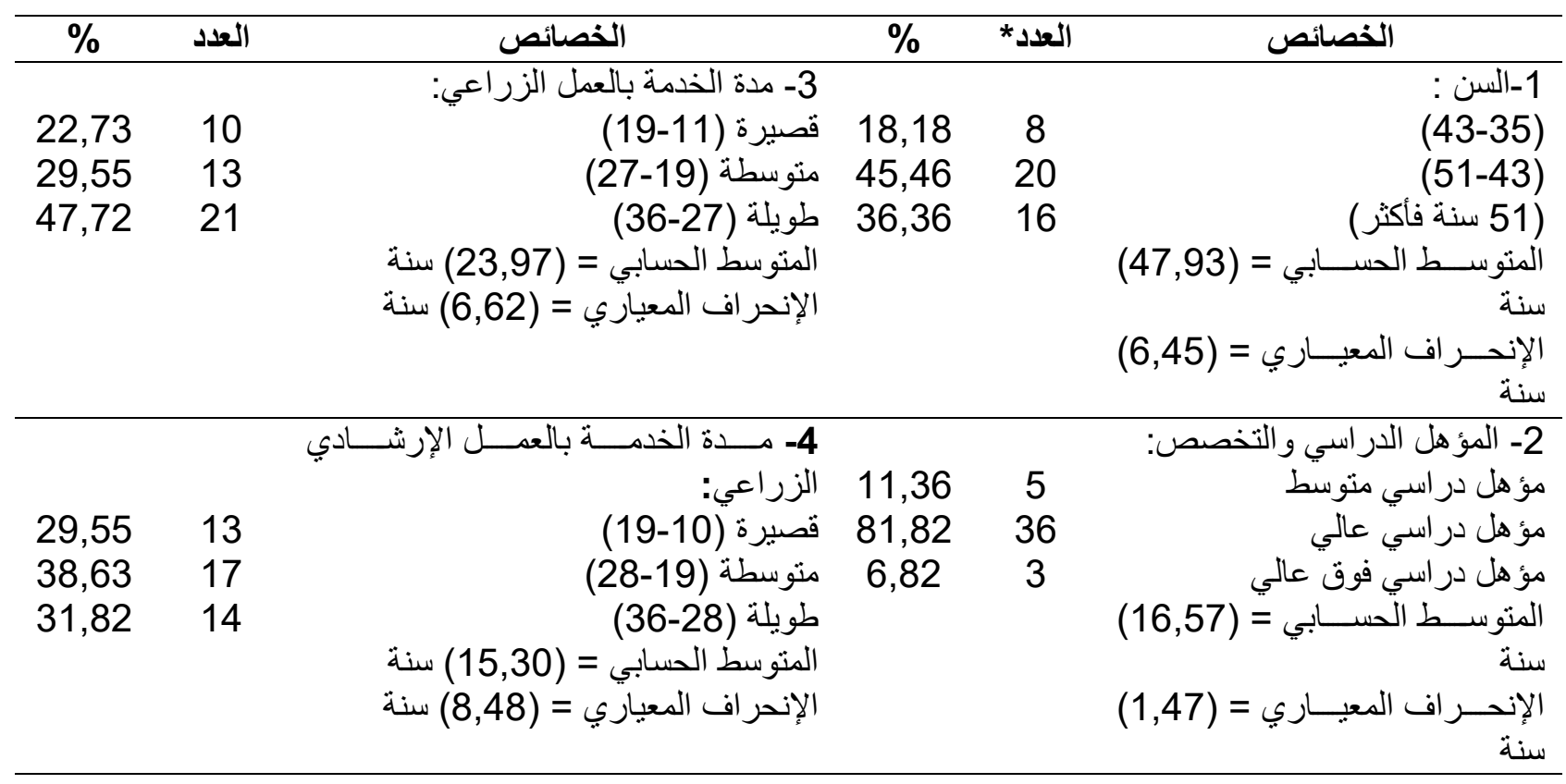
44 = العدد
المصدر : جمعت وحسبت من بيانات عينة الدراسة 
تابع جدول رقم (1). توزيع الأخصائيين الإششاديين الزراعيين المبحوثين وفقاً لخصائصهم الثخصية والمهنية

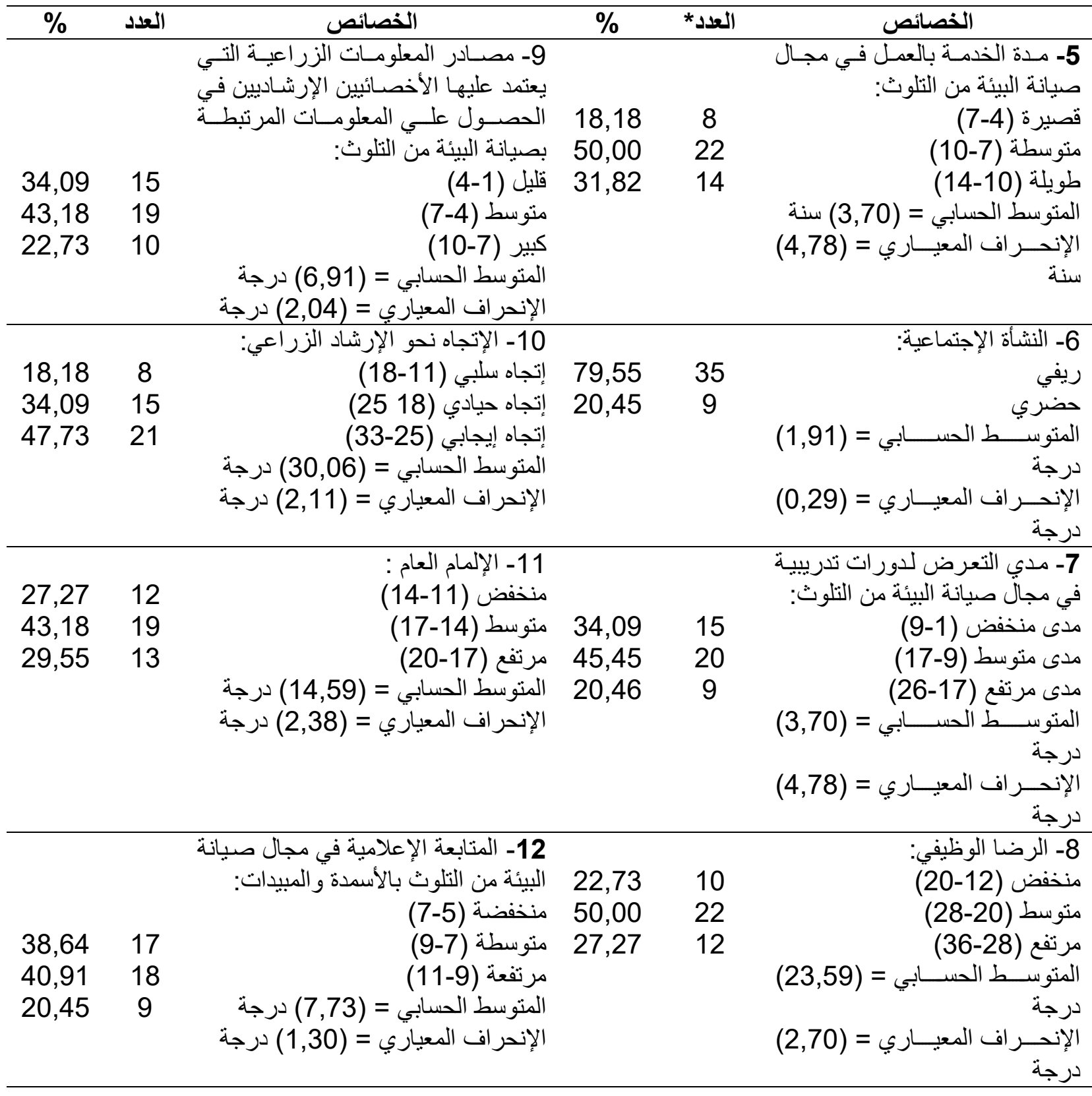

المصدر : جمعت وحسبت من بيانات عينة الدراسة

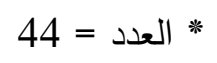

ثانياً: درجة الإحتياجات التعليمية للأخصائيين الإرشاديين النزاعيين في مجال التلوث البيئي بالمبيدات والأسمدة

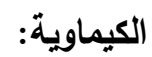

يتضح من جدول رقم (2) أن نسبة المبحوثين ذوبي الإحتياجات التعليمية المنذفضة فيما ينعلق بصيانة البيئة من

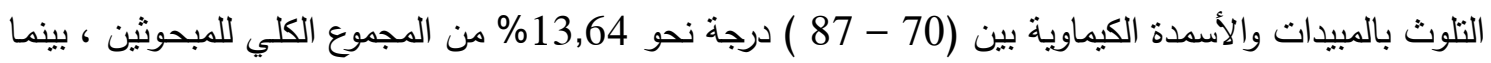

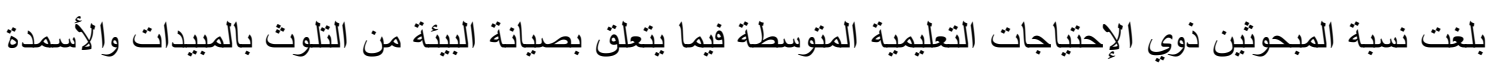
الكيماوية بين (87 - 104 ) درجة نحو 61,36\% من المجموع الكلي للمبحوثين ، في حين بلغت نسبة المبحوثين 
J. Adv. Agric. Res. (Fac. Agric. Saba Basha)

ذوي الإحتياجات التعليمية المرتفعة فيما يتعلق بصيانة البيئة من التلوث بالمبيدات والأسمدة الكيماوية بين (104) درجة فأكثر) نحو 25,00\% من المجموع الكلي للمبحوثين. 


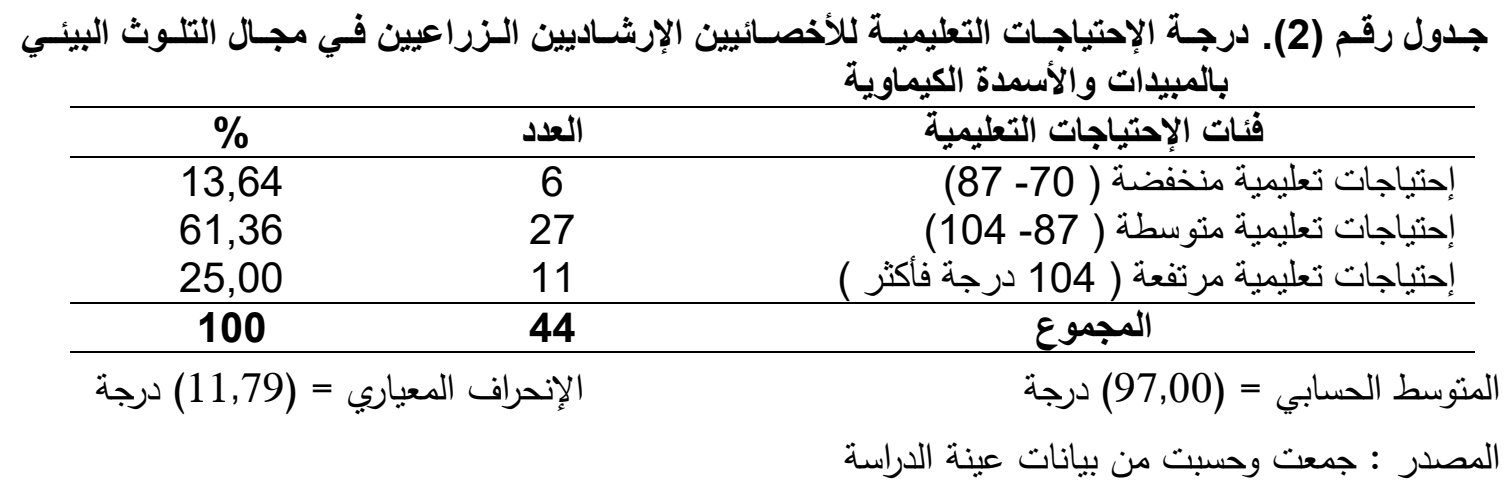

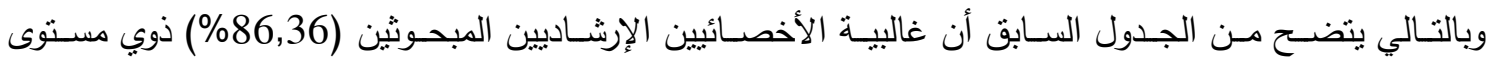

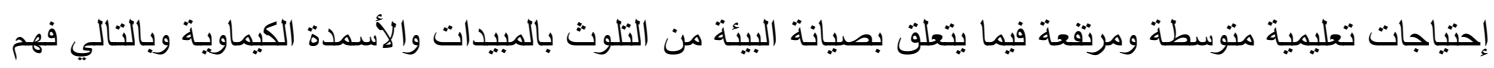
في إحتياج لعقد المزيد من الدورات التدريبية المتعلقة بصيانة البيئة ، وتخطيط المزيد من البرامج الإرشادية الزراعية

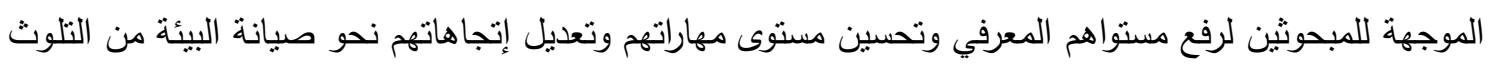

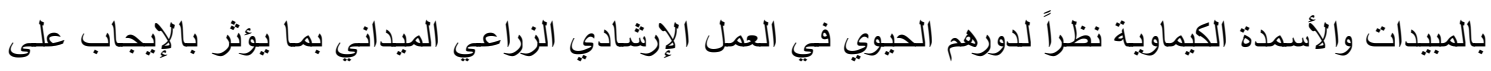

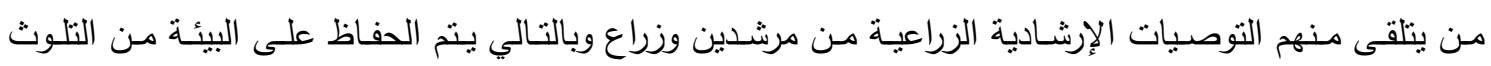
بالمبيدات والأسمدة الكيماوية وهذا من أهم حقوق الأجيال القادمة.

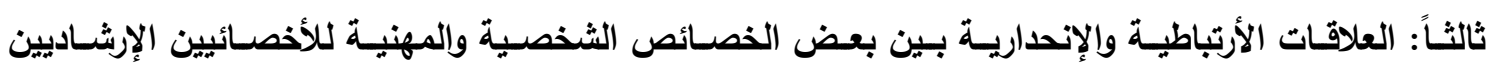
الزراعيين المبحوثين وبين درجة إحتياجاتهم التعليمية في مجال التلوث البيئي بالمبيدات والأسمدة الكيماوية 1- العلاقات الأرتباطية بين خصائص الأخصائيين الإرشاديين الزراعين دئنين المبحوثينين ودرجة إحتياجياتهم التعليمية

في مجال التلوث البيئي بالمبيدات والأسمدة الكيماوية: يتضـح من جدول رقم (3) عدم وجود علاقة إرتباطية بين درجـة الإحتياجات التعليميـة للأخصـائيين الإرشـاديين

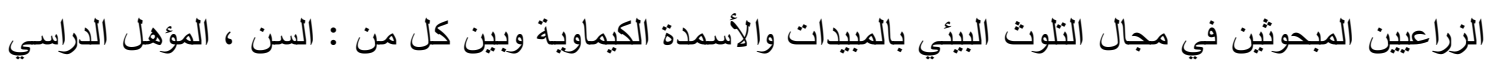

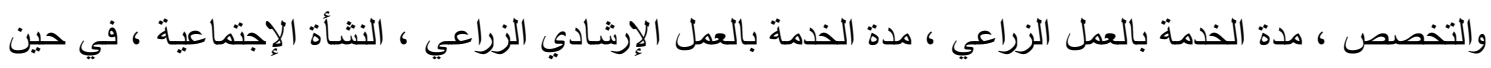

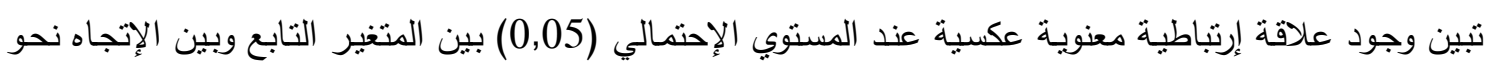

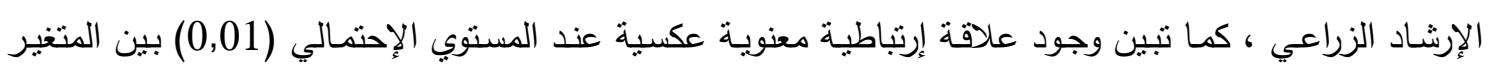

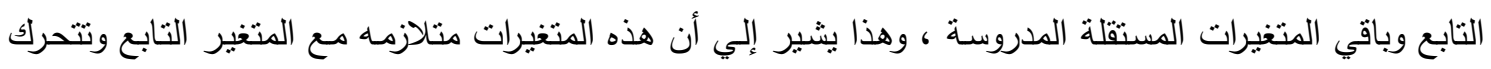

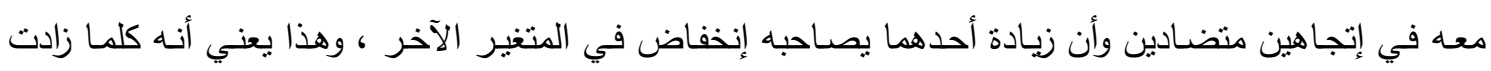

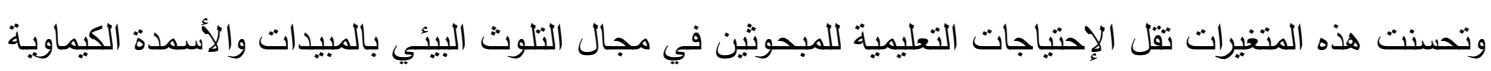

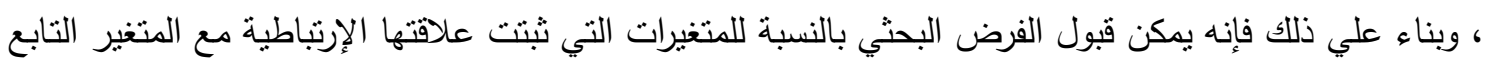
، ورفضاه بالنسبة لباقي المتغيرات . 
جدول رقم (3). قيم معامل الإرتباط البسيط بين درجة الإحتياجـات التعليمية للمبحوثين في مجال التلوث البيئي

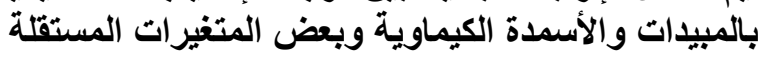

\begin{tabular}{|c|c|c|}
\hline معامل الإرتباط & 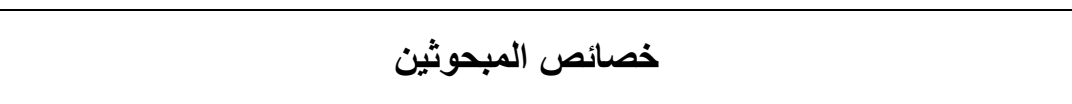 & p \\
\hline $0,158-$ & 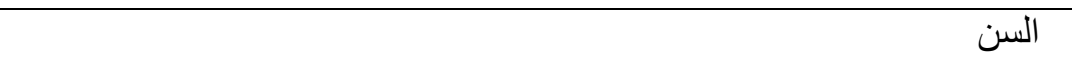 & 1 \\
\hline 0,106 & المؤهل الدر اسي و التخصص & 2 \\
\hline 0,105 & مدة الخدمة بالعمل الزراعي & 3 \\
\hline 0,165 & مدة الخدمة بالعمل الإرشادي الزر اعي & 4 \\
\hline${ }^{* *} 0,499$ & مدة الخدمة بالعمل في مجال صيانة البيئة من التلوث & 5 \\
\hline 0,061 & النشأة الإجتماعية & 6 \\
\hline${ }^{* *} 0,683-$ & مدي التعرض لدور ات تدرييية في مجال صيانة البيئة من التلوث & 7 \\
\hline$* * 0,558$ & & 8 \\
\hline${ }^{* *} 0,879$ & 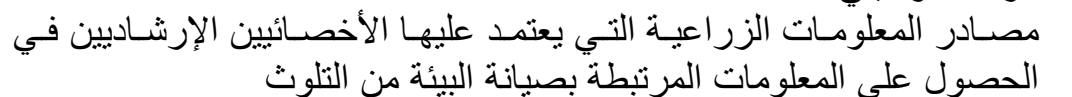 & 9 \\
\hline *0,398- & الإتجاه نحو الإرشاد الزر اعي & 10 \\
\hline **0,713- & الإلمام العام & 11 \\
\hline${ }^{* *} 0,466-$ & المتابعة الإعلامية في مجال صيانة البيئة من التلوث بالأسمدة و المبيدات & 12 \\
\hline$(0,05)$ & معنوية عند مستوى $(0,01)$ & ** \\
\hline
\end{tabular}

المصدر : جمعت وحسبت من بيانات عينة الدراسة

2- علاقة المتغيرات التفسيرية بلرجة الإحتياجـات التعليمية للأخصائيين الإششاديين الزراعيين المبحوثين في

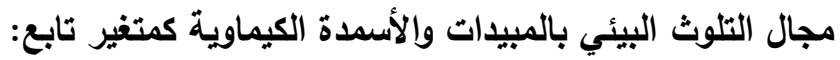

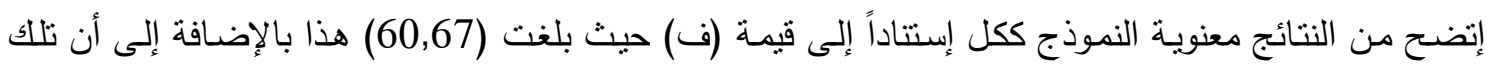
المتغيرات تساهم في تفسير حوالي (96\%) من التغيرات في درجة الإحتياجات التعليمية للأخصائيين الإرشاديين

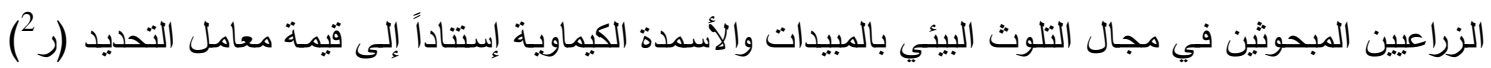

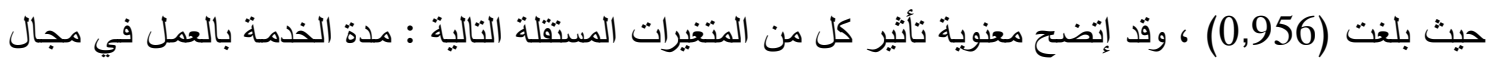
صيانة البيئة من التلوث ، الرضا الوظيفي ، مصادر المعلومات الزراعية التي يعتمد عليها الأخصائيين الإرشاديين

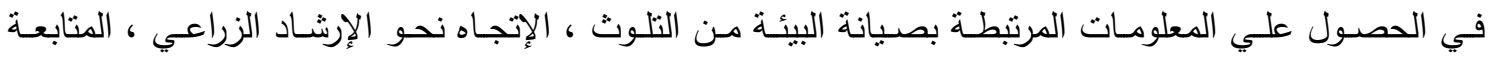
الإعلامية في مجال صبانة البيئة من التلوث بالأسمدة والمبيدات وذللك عند مستوي معنوية (0,01) إستتاداً إلى ملى

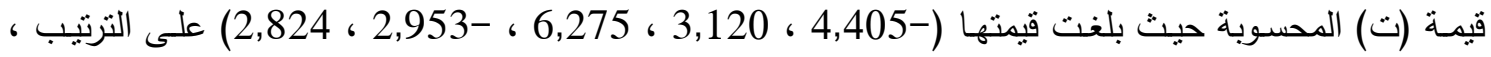
وإتضح أيضاً من هذا النموذج معنوية تأثثر كل من المتغيرات المستقلة النالية : مدي التعرض لدورات تدريبية في ،

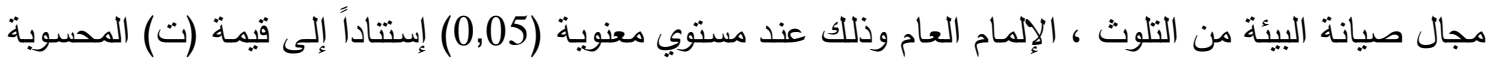
حيث بلغت قيمتها (2,023 ، -2,045 منيانه من ملى الترنيب. 
J. Adv. Agric. Res. (Fac. Agric. Saba Basha)

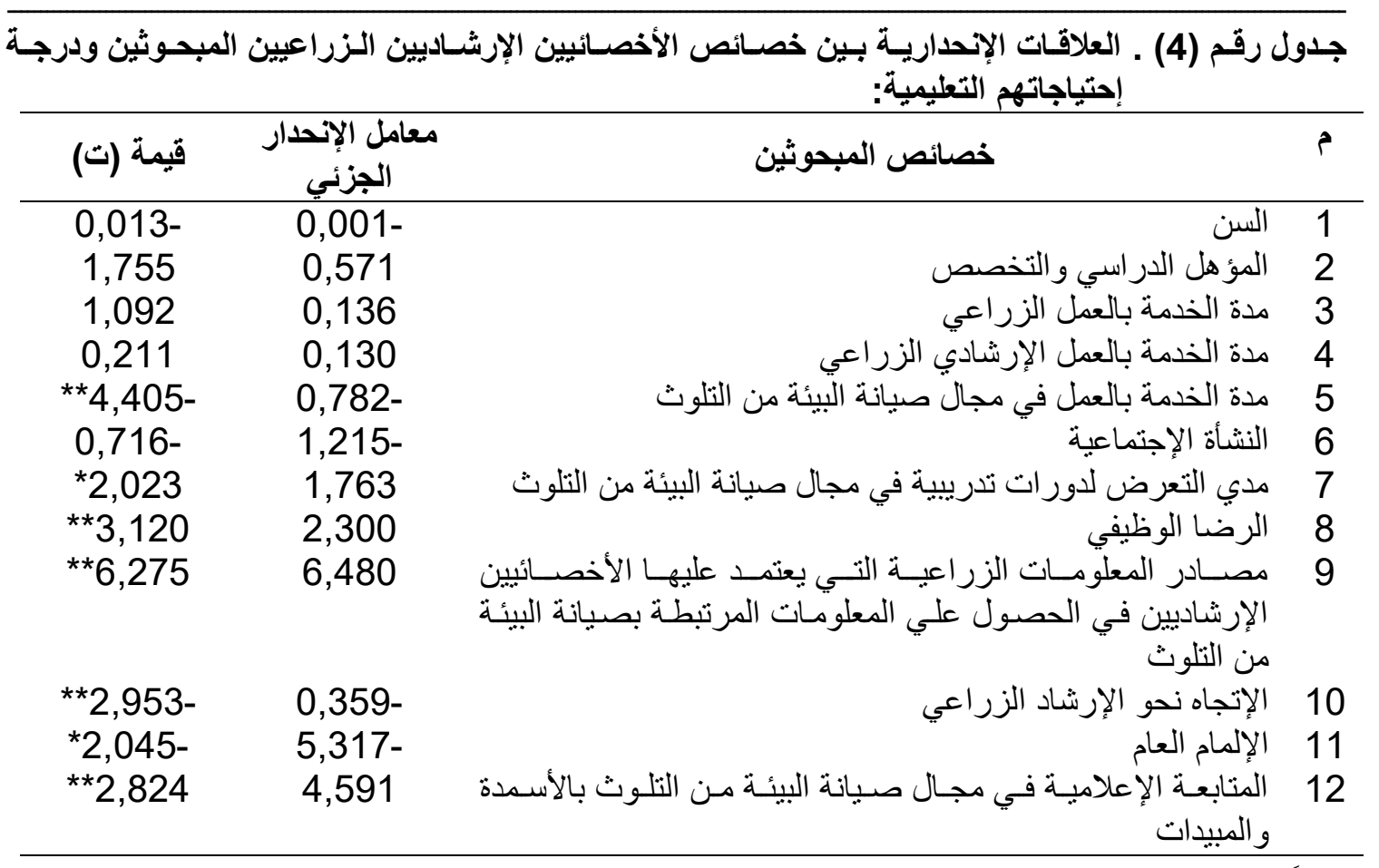

رابعاً : المشـاكل التي تواجـه الأخصائيين الإرشـاديين الزراعيين المبحوثين في مجال صيانة البيئة من التلوث والعلول المقترحة من وجهة نظرهم: ترجع أهمية دراسة المشاكل التي تواجه الأخصائيين الإرشاديين الزراعيين المبحوثين بهذه الدراسة إلى أن تضع أمام

متخذي القرار صورة مكتمله عن أهم المعوقات التي تحول دون إكتمال الخدمات الإرشادية التي توجه إليهح ، وتتعكس آثارها سلباً على البيئة ، وبالتالي تؤثر على العوائد التي يمكن أن تعود على البيئة لو نم إزالة أو حل هذه إنه

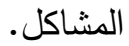

أولاً : المشاكل التي تواجه الأخصائيين الإرشاديين الزراعيين المبحوثين في مجال صيانة البيئة من التلوث: إتضـح من البيانات الواردة في الجدول رقم (5) أن هناك عشر مشـاكل تواجه الأخصائيين الإرشاديين الزراعيين

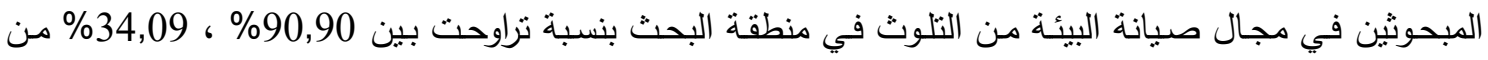

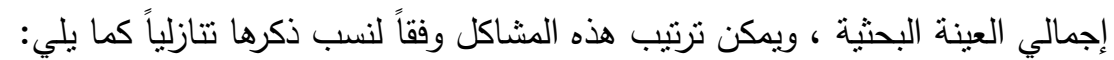

\begin{tabular}{|c|c|c|c|}
\hline$\%$ & 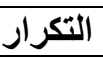 & 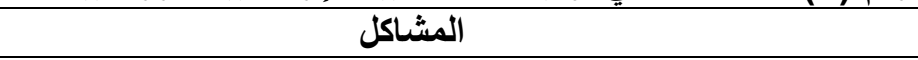 & r \\
\hline 90,90 & 40 & و المبيدات وجود دور ات تدريبية في مجال صيانة البيئة من التلوث بالأسمدة & 1 \\
\hline 86,36 & 38 & و المبيدات توفر نشرات إرشادية في مجال صيانة البيئة من التلوث بالأسمدة & 2 \\
\hline 81,81 & 36 & عدم المعرفة بقو اعد الإستخدام الآمن للأسمدة والمبيدات & 3 \\
\hline 79,54 & 35 & عدم توفر ملصقات أو مطويات للتو عية بتلوث البيئة & 4 \\
\hline 68,18 & 30 & قلة المعرفة بالمبيدات المحرمة دولياً و الملوثة للبيئة & 5 \\
\hline 59,09 & 26 & عدم قناعة المزارعين بإستخدام بدائل المبيدات الكيماوية & 6 \\
\hline 50,00 & 22 & الإستخدام المفرط من قبل الزر اع للأسمدة والمبيدات & 7 \\
\hline 45,45 & 20 & التوصيات الخاطئة لمحلات بيع الأسددة و المبيدات & 8 \\
\hline 38,63 & 17 & قلة الحوافز الخاصة بالعمل الإرشادي الزر اعي & 9 \\
\hline 34,09 & 15 & صعوبة تغيير سلوك الزراع & 10 \\
\hline
\end{tabular}

حسبت النسبة المئوية من إجمالي عدد الأخصائيين الإرشاديين الزراعيين المبحوثين البالغ عددهم (44) أخصائياً 
ثانياً: الحلول المقترحة من وجهة نظر الأخصائيين الإرشاديين الزراعيين المبحوثين:

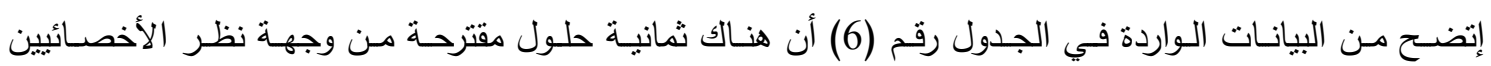

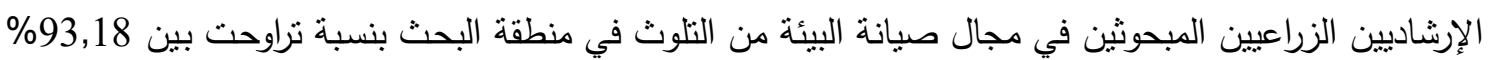

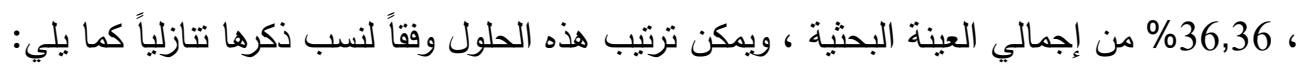

\begin{tabular}{|c|c|c|c|}
\hline$\%$ & 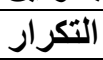 & الحلول & r \\
\hline 93,18 & 41 & وضع برنامج تدريبي شامل لجميع الأخصائيين في مختلف التخصصات & 1 \\
\hline 84,09 & 37 & توفير نشر ات إرشادية وملصقات للتو عية بأهمية الَّفاظ على البيئة & 2 \\
\hline 77,27 & 34 & توفير المركبات الحيوية للحد من إستخدام المبيدات & 3 \\
\hline 72,72 & 32 & نشر ثقافة الزر اعة النظيفة & 4 \\
\hline 65,90 & 29 & و أضرار وزارة البيئة مع كافة الوزارات و الهيئات لعقد ندوات للتو عية بأسباب & 5 \\
\hline 54,54 & 24 & تو عية الزر اع لإستخدام بدائل المبيدات و المخصبات الحيوية & 6 \\
\hline 45,45 & 20 & تحديد قائمة بأسماء المبيدات و الأسمدة المحرمة دولياً & 7 \\
\hline 36,36 & 16 & إتباع الدورة الزر اعية & 8 \\
\hline
\end{tabular}

الخولي ، سالم إبراهيم ، 2007 ، المشكلات الإجتماعية المعاصرة في المجتمع المصري ، دار الندى للطباعة ، الطبعة الأولى ، القاهرة. العادلي ، أحمد السيد ، 1972، أساسيات علم الإرشاد الزراعي ، دار المطبوعات الجديدة ، الإسكندرية.

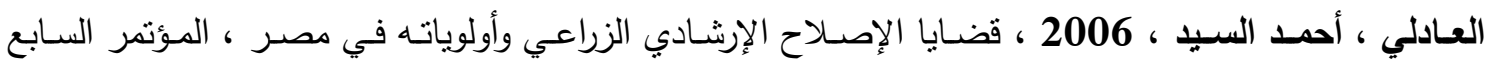

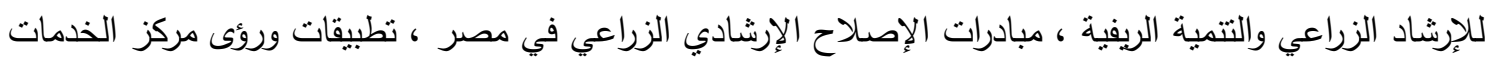

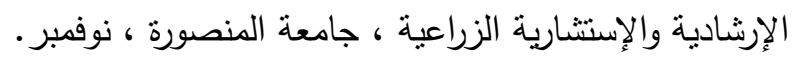
طلبة ، ليلى أنور ، فؤاد خليل أبو العنين ، صفاء أحمد فهيم ،

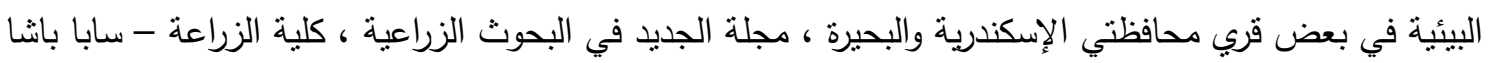

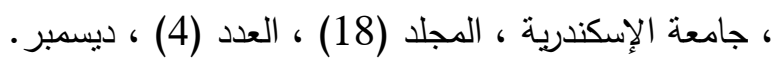

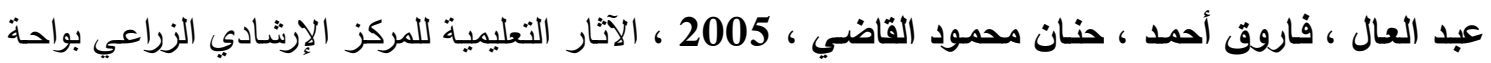

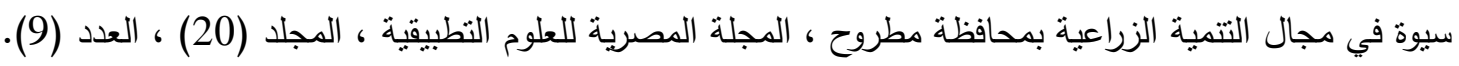
قثطة ، عبد الحليم عباس ، 2012 ، الإرشاد الزراعي رؤية جديدة ، كلية الزراعة ، جامعة القاهرة. قثطة ، عبد الحليم عباس ، 2013 ، فلسفة الإرشاد الزراعي الناجح في الدول النامية ، كلية الزراعة ، جامعة الزئة

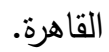

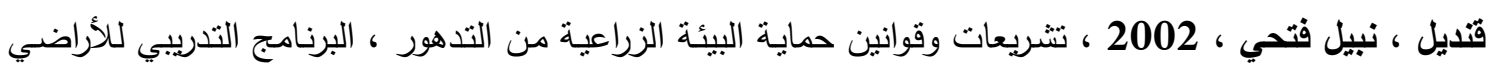
المنأثرة بالأملاح ، معهد بحوث الأراضي والمياه ، المجلة العربية ، القاهرة ، أغسطس.

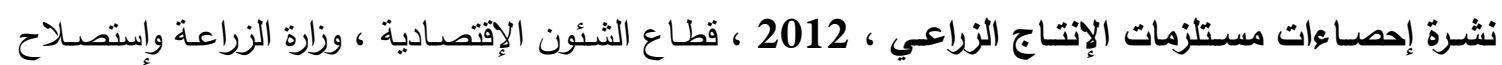
الأراضي ، جمهورية مصر العربية. 
Patil S. S. and. Kokate . K.D. 2011 . Training Need Assessment of Subject Matter Specialists of Krishi Vigyan Kendras, Res. J. Ext. Edu. 11 (1), January, India, (10-25).

Anaeto F.C, Asiabaka C.C, Nnadi F.N, Ajaero J.O, Aja O.O, Ugwoke F.O, UkpongsonM.U, Onweagba A.E. 2012 . The role of extension officers and extension services in the development of agriculture in Nigeria, May, Federal University of Technology Owerri Imo state Nigeria , (89-110).

\title{
A Study of Educational Needs of Agricultural Extension Subject Matter Specialists (S.M.S) in the Area of Environmental Pollution and some of the Factors affecting them in Beheira Governorate
}

\author{
Kamal Salah Issa Saker \\ Department of Agricultural Economics - Faculty of Agriculture (Saba Basha) - \\ Alexandria University
}

\begin{abstract}
:
This research is aimed mainly to study the educational needs of Agricultural Extension Subject Matter Specialists (S.M.S) in the field of environmental pollution concerning the use of pesticides and chemical fertilizers in El-Beheira governorate

Data was collected through personal interview for all Agricultural Extension Subject Matter Specialists (S.M.S) in El- Beheira governorate and their numbers were (44) Respondents , The statistical methods used were: mean, frequency tables, percentages, simple correlation coefficient (Pearson), and multiple regression coefficient.
\end{abstract}

\section{The most important results as following:}

- About (86.36\%) with medium and high levels of educational needs in relation to the maintenance of the environment from pesticide contamination and chemical fertilizers.

- Data showed a significant inverse correlation between the degree of educational needs for S.M.S in the field of environmental pollution concerning the use of pesticides and chemical fertilizers, and the following variables: service life work in the field of environmental protection from pollution, the extent of exposure to training courses in the field of environmental protection from pollution, job satisfaction, Agricultural sources of information relied upon by S.M.S to obtain the information related to the protection of the environment from pollution, attitudes toward agricultural extension, public familiarity, media follow up in the field of environmental protection from pollution like fertilizers and pesticides.

- Data indicate that the presence of some of the problems faced S.M.S in the field of environmental pollution concerning the use of pesticides and chemical fertilizers, the most important for instance, Lack of training courses in the field of environmental protection from pollution like fertilizers and pesticides, Lack of guidance bulletins in the field of environmental protection from pollution like fertilizers and pesticides, Lack of knowledge of the rules of safe use of fertilizers and pesticides, The lack of posters or brochures to raise awareness of the pollution of the environment. 